\title{
Lembaga Pemasyarakatan AnaK Daerah Istimewa Yogyakarta Sebagai Wadah PembinaAn KebersamaAn Untuk Menumbuhkan Toleransi Menggunakan Pendekatan Perilaku Dalam Arsitektur
}

\author{
Andhika Prasetya B, M.D.E. Purnomo, Agus Sanyoto Widodo \\ Program Studi Arsitektur \\ Jurusan Arsitektur Fakultas Teknik \\ Universitas Sebelas Maret Surakarta \\ Email : andhi.prabu@gmail.com
}

\begin{abstract}
Abstarct : Children penitentiary Special Region of Yogyakarta (LPA DIY) is a container or a correctional system (facility) guidance system that emphasizes togetherness to instill tolerance to protégé age 12-18 years in the coverage area of Special Region of Yogyakarta (DIY), the behavior of the design strategy architecture. The purpose LPA D.I.Y design of is to get a facility of LPA DIY that design in accordance with the penal system together to foster tolerance. LPA design problems DIY is how the physical form of facility LPA DIY in accordance with the penal system together to foster tolerance.

The method used is a programming architecture. Behavioral approach in architecture is used as a strategy to solve design problems LPA DIY by directing the behavior of protégé correctional desired direction through variables such as the shape of the room, furniture arrangement, color selection and certain textures. Behavioral approach emphasizes the dialectical relationship among space, human and society that used that space. Behavior in architecture related to the characteristics, age, and state of their psychological and coaching facilities in the LPA DIY. The result is the design of the facility LPA $D I Y$ that embodies the correctional function adapted to the characteristics of community correctional protégé by using a variable space to direct the behavior of protégé correctional desired direction so that the activities of correctional run optimally and does not cause aberrant behavior in correctional protégé.
\end{abstract}

Keywords: Children penitentiary, protégé, and behavior in the architecture.

\section{PENDAHULUAN}

Konsep pemasyarakatan berbeda dengan konsep penjara. Konsep pemasyarakatan adalah membuat orang menyesali perbuatannya dan setelah kembali ke masyarakat bisa terintegrasi dengan masyarakat, sedangkan konsep penjara adalah membuat orang jera. Idealnya pewadahan kegiatan pemasyarakatan menggunakan fasilitas yang direncanakan dan dirancang untuk pemasyarakatan, namun dalam banyak kasus di Indonesia umumnya dan di DIY khususnya, menggunakan fasilitas penjara untuk mewaadahi sistem pemasyarakatan.

Sistem pembinaan di lembaga pemasyarakatan memerlukan hubungan yang baik antara 3 pelaku pemasyarakatan yaitu anak didik, petugas pemasyarakatan dan masyarakat. Sistem pembinaan akan efektif ketika tiga elemen ini secara bersama-sama mendukung proses pemasyarakatan. Kebersamaan antara pelaku pemasyarakatan ini ditujukan untuk menumbuhkan toleransi pada anak didik yang mana anak didik adalah objek dari pembinaan di lembaga pemasyarakatan anak (LPA).

Toleransi merupakan pijakan awal dalam pembinaan moral. Banyak kasus kenakalan anak juga dipengaruhi dengan hilangnya toleransi yang dialami oleh anak itu. Seperti dalam kasus kejahatan asusila, pencurian dan penyalahgunaan narkotika, hilangnya waktu bersama orang tua menjadi faktor yang sangat dominan. Sedangkan pada kasus premanisme dan kekerasan, rasa toleransi yang hilang dari anak menjadi faktor dominan. Toleransi di sini diperlukan untuk menyesuaikan tingkah laku yang ditempuh seseorang, menyeimbang kan antara pemenuhan hasrat dan kepemilikan dengan norma-norma yang berlaku di masyarakat sehingga seseorang dapat kembali ke keadaan tenang dengan mempuh tingkah laku yang sesuai dengan norma yang berlaku. (Wawancara dengan Ka. Sub. Bag. TU lembaga pemasyarakatan kelas II A Jawa Tengah, Sri Lestari, BC.IP. 2010) 
Pembinaan untuk anak didik berbeda dengan pembinaan untuk orang dewasa. Anak berusia 12-18 tahun memiliki fase perkembangan, perilaku dan karakteristik yang berbeda dari orang dewasa. Fase perkembangan anak dapat diartikan sebagai penahapan atau pembabakan rentang perjalanan individu yang diwarnai ciriciri khusus atau pola-pola tingkah laku tertentu. Beberapa ahli melakukan pembagian yang berbeda-beda atas fase perkembangan, namun secara umum dapat digolongkan menjadi tiga yaitu berdasarkan analisa biologis (fisiologis), disaktis (rasa aman) dan psikologis. Dalam hubungannya dengan proses pendidikan, perkembangan individu sejak lahir melewati fase-fase seperti tertulis pada tabel 1: $(\mathrm{N}$, Syamsu Yusuf L, 2007)

Tabel 1. Fase Perkembangan

\begin{tabular}{|l|l|}
\hline Tahap Perkembangan & Usia \\
\hline Masa Prasekolah & 0-6 tahun \\
Masa Sekolah Dasar & 6-12 tahun \\
Masa Sekolah Menengah & 12-18 tahun \\
Masa Dewasa & $18-21$ tahun \\
\hline
\end{tabular}

Sumber: N, Syamsu Yusuf L, 2007

Anak berusia 12-18 tahun berdasarkan fase perkembangannya berada dalam klasifikasi perkembangan masa sekolah menengah atau tahap remaja awal. Ini merupakan fase awal transisi dari masa kanak-kanak ke masa dewasa. Dalam fase ini, anak mulai kehilangan karakter anak-anaknya dan mulai mencari karakter dewasanya. Pada masa ini, seorang anak juga mengalami kematangan secara genital. Dalam pengertian lain, pada fase ini anak sedang mengalami ketidak seimbangan keadaan psikis dan mengalami kematangan genital yang itu baru untuknya sehingga mudah sekali terpengaruh dengan apa saja yang ada disekitarnya. Pengaruh inilah yang kemudian membuat anak kurang berhasil menjalankan tugas-tugas perkembangan sesuai tingkatannya dan melakukan penyimpangan dalam berperilaku di masyarakat.

Perilaku menyimpang anak dapat dikatagorikan menjadi 2 berdasarkan hubungan dengan hukum yang berlaku yaitu perilaku menyimpang anak yang bersifal amoral anti sosial dan perilaku menyimpang anak yang bersifat melanggar hukum. Perilku menyimpang yang melanggar hukum, membuat anak masuk kedalam LPA.
Perilaku menyimpang pada anak, secara umum dikarenakan oleh 2 faktor atau stimulus. Pertama stimulus internal dan eksternal. Freud berpendapat bahwa stimulus dari dalam merupakan faktor dominan untuk menggerakkan seseorang, sedangkan stimulus dari luar juga memberi peranan walaupun tidak sebesar dari dalam, namun pada saat-saat tertentu, stimulus dari luar juga dibutuhkan pada keadaan tertentu (Freud, dalam Hall dan Gardner Lindzey : 1993. hal: 69-72).

Pendekatan perilaku dalam menentukan sistem pewadahan kegiatan menekankan keterkaitan dialektik antara ruang sebagai sistem pewadahan (setting) dan pelaku yang memanfaatkan atau menghuni ruang tersebut. Pendekatan ini menekankan perlunya memahami perilaku manusia yang berbedabeda dalam memanfaatkan ruang. Ruang dalam pendekatan ini memiliki arti dan nilai yang berbeda tergantung dari apresiasi dan kognisi pelaku dalam ruang tersebut, sehingga karakteristik tertentu pada pelaku menghasilkan konsep dan wujud ruang yang berbeda (Rapoport, dalam Haryadi dan B. Setyawan, 2010).

DIY membutuhkan LPA yang dapat mewadahi sistem pembinaan kebersamaan untuk menumbuhkan toleransi pada pelaku dalam LPA. Hal ini diwujudkan dalam wujud fisik LPA DIY yang mampu mewadahi kegiatan pembinaan kebersamaan dan mengarahkan perilaku pelaku LPA melalui variabel ruang yang berpengaruh pada perilaku. Selain itu, wujud fisik LPA juga harus disesuaikan dengan karakteristik perilaku dari pelaku pemasyarkatan supaya tidak menimbulkan perilaku yang tidak wajar pada pelaku LPA.

\section{METODE}

Metode pembahasan dilakukan dengan menggunakan metode analisa dengan proses pemikiran deduktif, untuk kemudian ditarik kesimpulan yang ideal.

1. Gagasan awal

Gagasan awal merupakan ide utama yaitu dari adanya sebuah fenomena bahwa kondisi bangunan LPA yang ada saat ini belum mampu mendukung dari proses pemasyarakatan anak didik yang telah di gariskan oleh pemerintah. Dari fenomena ini kemudian dikembangkan menjadi sebuah ide perencanaan dan perancangan 
lingkungan binaan arsitektural berupa sebuah desain LPA dengan pendekatan aspek perilaku dalam arsitektur yang mendukung proses rehabilitasi anak didik.

2. Penelusuran Masalah

Dari gagasan awal yang berdasarkan pada sebuah fenomena, kemudian merencanakan bagaimana sebuah LPA yang ingin dikembangkan dalam situasi ideal seperti yang dikehendaki. Penelusuran masalah juga didapat dari merekam dan mengamati kondisi anak didik dalam tahanan dan setelah keluar dari tahanan, mengamati fase perkembangan, proses perilaku dan interaksi sosial anak secara umum, menelusuri kemungkinankemungkinan yang dapat ditangkap dan diterjemahkan dalam rancangan arsitektur, yang dipertemukan dengan kaidah-kaidah normatif/teori-teori yang terkait.

Selain itu, dilakukan juga studi literatur dengan mencari data melalui media cetak, elektronik untuk mendapatkan issue-issue yang sedang berkembang serta berita yang dapat dijadikan acuan dan juga menambah kekuatan dan keakuratan.

3. Pengumpulan data

Metode pembahasan dilakukan dengan menggunakan metode analisa dengan proses pemikiran deduktif, untuk kemudian ditarik kesimpulan yang ideal, melalui tahap-tahap sebagai berikut

a. Kepustakaan (Literatur)

Pengumpulan data dan informasi dari beberapa buku, literatur dari media massa (baik media elektronik maupun cetak) dan beberapa data dari lembaga/instansi terkait sebagai referensi dalam menyusun konsep perencanaan dan perancangan.

b. Observasi

Melakukan pengamatan untuk mengetahui kondisi empiris di lapangan.

c. Teknik Wawancara

Melakukan wawancara dengan pihak yang terkait atau pihak yang dapat memberikan data informasi positif dan dapat dipertanggung jawabkan.

d. Teknik dokumentasi

Melakukan dokumentasi objek penelitian berkaitan dengan kondisi empiris
4. Pengolahan data dan informasi

Data dan informasi yang diperoleh pada mulanya diklasifikasikan sesuai dengan tema, kemudian direduksi menjadi substansi-substansi yang dianggap penting dan digunakan dalam penulisan konsep perencanaan dan perancangan desain. Pengolahan data ini berlangsung terusmenerus karena adanya tambahan dan informasi baru serta pengurangan akibat adanya perubahan yang membuat data sebelumnya dianggap kurang sesuai dengan format yang baru.

5. Pendekatan dan rumusan konsep perencanaan

Pendekatan dan perumusan konsep Perencanaan melalui metoda induktif, yaitu pendekatan berdasarkan pengalaman empirik untuk memperoleh gambaran mengenai LPA DIY dan metoda deduktif yaitu pendekatan berdasarkan teoritik yang membantu mengarahkan pembahasan sesuai dengan perencanaan yang diinginkan.

6. Pendekatan dan rumusan konsep perancangan

Metoda yang digunakan dalam pendekatan konsep perancangan adalah metode analisis. Metode ini menguraikan dan mengkaji dari data-data dan informasi yang kemudian digunakan sebagai data relevan bagi perancangan. Pada tahapan ini dilakukan dengan analisis data menggunakan metode analisis deskriptif yaitu melalui penguraian data dan informasi yang disertai gambar sebagai media berdasar pada teori normative yang ada.

Tahapan analisa akan dilakukan pengolahan data-data yang telah terkumpul dan dikelompokan berdasarkan program fungsional, performasi dan arsitektural.

a. Program fungsional bertujuan untuk mengidentifikasi pengguna yang ada di LPA DIY yaitu pengguna, kegiatan pengguna dan alur kegiatan pengguna.

b. Program performasi menerjemahkan secara skematik kebutuhan pengguna LPA DIY beserta fasilitasnya kedalam peryataan persyaratan karakteristik respon lingkungan binaan (tolak ukur kinerja). Dalam hal ini membahas persyaratan kebutuhan ruang, 
persyaratan ruang dan program ruang dalam bangunan lembaga pemasyarakatan anak

c. Pemrograman arsitektural merupakan tahap pengagabungan dari hasil identifikasi kedua analisis sebelumnya (fungsional dan performasi). Dalam proses ini akan menganalisis masalah massa, ruangan, tampilan, pengolahan tapak, utilitas dan struktur bangunan yang menyatukan akan kebutuhan penghuni dengan pesyaratan yang ada.

7. Konsep perancangan

Konsep perancangan menggunakan metoda sintesis, yaitu memadukan hasil analisis sehingga mendapatkan hal baru yang kemudian disebut konsep perencanaan yang siap untuk ditransformasikan kedalam bentuk ungkapan fisik yang dikehendaki.

\section{ANALISA}

\subsection{Analisa kebutuhan ruang dan lahan}

Kebutuhan lahan dihitung dengan menggunakan KDB Kabupaten Sleman pada area resapan air yaitu 0,4 sebagai berikut:

Tabel 2.Kebutuhan Ruang dan Lahan LPA DIY.

\begin{tabular}{|c|c|c|c|}
\hline $\begin{array}{l}\mathrm{N} \\
\mathrm{O}\end{array}$ & $\begin{array}{l}\text { Kelompok } \\
\text { Ruang }\end{array}$ & $\begin{array}{l}\text { Kebutuhan } \\
\text { Ruang }\left(\mathrm{m}^{2}\right)\end{array}$ & $\begin{array}{l}\text { Kebutuhan } \\
\text { Lahan }\left(\mathrm{m}^{2}\right)\end{array}$ \\
\hline 1. & $\begin{array}{l}\text { Pengelolaan } \\
\text { gedung } 1\end{array}$ & 365,15 & 912,88 \\
\hline 2. & $\begin{array}{l}\text { Pengelolaan } \\
\text { gedung2 }\end{array}$ & 389,15 & 972,88 \\
\hline 3. & $\begin{array}{l}\text { Hunian anak } \\
\text { didik }\end{array}$ & 3378,67 & 8446,68 \\
\hline 4. & $\begin{array}{l}\text { Hunian } \\
\text { dinas } \\
\text { pegawai }\end{array}$ & 1218,00 & 3045,00 \\
\hline 5. & Pembinaan & 9798,50 & 24496,25 \\
\hline 6. & $\begin{array}{l}\text { Penunjang / } \\
\text { Servis }\end{array}$ & 737,86 & 1844,65 \\
\hline 7. & Kunjungan & 300,55 & 751,38 \\
\hline 8. & Parkir & 1014,00 & 2535,00 \\
\hline & Total & 17201,88 & 43004,70 \\
\hline
\end{tabular}

\subsection{Analisa Pemilihan Lokasi dan Tapak}

Analisa lokasi merujuk pada arahan yang diberikan Kanwil Hukum dan HAM DIY yaitu di Kecamatan Pakem, Kabupaten Sleman, berdekatan dengan lapas kelas IIA narkotika DIY.
Kriteria yang harus dipenuhi dalam penentuan lokasi untuk bangunan LPA DIY antara lain:

a. Letak diluar/ di pinggir kota, mudah terjangkau dengan sarana transportasi dan telekomunikasi, fasilitas penerangan serta air bersih.

b. Areal menurut rencana umum tata ruang kota yang dikeluarkan pemda setempat

c. Luas tapak LP Kelas IIA minimal $40.000 \mathrm{~m} 2$.

d. Luas bangunan LP kelas IIA minimal $14.000 \mathrm{~m} 2$ dan terletak di bagian tengah tapak.

e. Bebas atu jauh dari pemukiman tertimpa bencana alam (gempa , banjir dan longsor) dan pembuangan air limbah lancar dengan tidak merusak lingkungan.

f. Sedapat-dapatnya dekat dengan markas Kepolisian, Kejaksaan dan Pengadilan.

Tapak terpilih terletak di depan RSJ Ghrasia, Pakem, Kabupaten Sleman. Sebelah utara dan selatan tapak berbatasan dengan lahan pertanian dan pemukiman warga. Sebelah timur berbatasan dengan Jalan Kaliurang km.17 dengan lebar jalan $10 \mathrm{~m}$. Sebelah barat tapak berbatasan dengan lahan persawahan.

Tapak dengan luasan $43.750 \mathrm{~m}^{2}$ berupa lahan persawahan yang beberapa bagian telah dikeringkan. Kontur pada tapak relatif datar dengan terasiring antara $50 \mathrm{~cm}$. Tidak terdapat tanaman besar yang dapat dimanfaatkan.

Sebelah timur tapak terdapat saluran drainase kota, di tepi Jalan Kaliurang. Keadaan lalulintas di Jalan Kaliurang relatif sepi dengan tingkat kebisingan relatif rendah.

\subsection{Analisa Pengolahan Tapak}

\subsubsection{Analisa tapak terhadap sistem keamanan}

Pendekatan sistem keamanan dapat dari beberapa faktor, antara lain perencanaan arsitektural, pengawasan petugas dan bantuan peralatan keamanan.

Kriteria desain untuk mengoptimalkan sistem keamanan di LPA DIY antara lain: a. Sesuai dengan peraturan pemerintah yang tertuang pada Keputusan 
Menteri Kehakiman dan Hak Asasi Manusia No. M.01.PL.01.01 tentang pola bangunan UPT. Pemasyarakatan.

b. Mengelompokkan keamanan ruang kedalam zona pengawasan tertentu.

c. Memudahkan pengawasan kegiatan secara langsung oleh petugas.

Kebutuhan keamanan di LPA D.I.Y dapat dikelompokkan kedalam tiga bagian yaitu zona yang membutuhkan kemanan (security area), zona yang membutuhkan keamanan terbatas (semi security area) dan zona yang tidak membutuhkan kemanan (non security area).

Keamanan pada zona security, semi security dan non security berjenjang mulai dari minimum, medium hingga maksimum tergantung jenis kegiatan yang berlangsung.

Tabel 3.Kebutuhan Keamanan LPA DIY.

\begin{tabular}{|c|c|c|c|c|}
\hline No & $\begin{array}{l}\text { Kelompok } \\
\text { Ruang }\end{array}$ & Jenis Ruang & $\begin{array}{l}\text { Zona } \\
\text { Kemanan }\end{array}$ & $\begin{array}{l}\text { Keaman } \\
\text { an }\end{array}$ \\
\hline \multirow[t]{3}{*}{1.} & \multirow{3}{*}{$\begin{array}{l}\text { Ruang } \\
\text { pengelolaan } \\
\text { lapas } \\
\text { gedung 1 }\end{array}$} & R. Kalapas & \multirow{3}{*}{$\begin{array}{l}\text { Non } \\
\text { security } \\
\text { area }\end{array}$} & Medium \\
\hline & & $\begin{array}{l}\text { R. Unit } \\
\text { umum }\end{array}$ & & Medium \\
\hline & & $\begin{array}{l}\text { R. Keamanan } \\
\text { dan ketertiban }\end{array}$ & & Medium \\
\hline \multirow[t]{2}{*}{2.} & \multirow[t]{2}{*}{$\begin{array}{l}\text { Parkir } \\
\text { kendaraan }\end{array}$} & $\begin{array}{l}\text { Parkir } \\
\text { pengunjung }\end{array}$ & \multirow{2}{*}{$\begin{array}{l}\text { Non } \\
\text { security } \\
\text { area }\end{array}$} & $\begin{array}{l}\text { Minimu } \\
\mathrm{m}\end{array}$ \\
\hline & & $\begin{array}{l}\text { Parkir } \\
\text { pengelola }\end{array}$ & & $\begin{array}{l}\text { Minimu } \\
\mathrm{m}\end{array}$ \\
\hline \multirow[t]{2}{*}{3.} & \multirow[t]{2}{*}{$\begin{array}{l}\text { Pembinaan } \\
\text { asimilasi }\end{array}$} & $\begin{array}{l}\text { Arena } \\
\text { pertunjukan }\end{array}$ & \multirow{2}{*}{$\begin{array}{l}\text { Non } \\
\text { security } \\
\text { area }\end{array}$} & $\begin{array}{l}\text { Minimu } \\
\mathrm{m}\end{array}$ \\
\hline & & $\begin{array}{l}\text { Lapangan } \\
\text { olah raga }\end{array}$ & & $\begin{array}{l}\text { Minimu } \\
\mathrm{m}\end{array}$ \\
\hline \multirow[t]{2}{*}{4.} & \multirow[t]{2}{*}{$\begin{array}{l}\text { Hunian } \\
\text { dinas }\end{array}$} & $\begin{array}{l}\text { Hunian } \\
\text { Kalapas }\end{array}$ & \multirow{2}{*}{$\begin{array}{l}\text { Non } \\
\text { security } \\
\text { area }\end{array}$} & $\begin{array}{l}\text { Minimu } \\
\mathrm{m}\end{array}$ \\
\hline & & $\begin{array}{l}\text { Hunian Ka. } \\
\text { unit }\end{array}$ & & $\begin{array}{l}\text { Minimu } \\
\mathrm{m}\end{array}$ \\
\hline \multirow[t]{6}{*}{5} & \multirow[t]{6}{*}{$\begin{array}{l}\text { Ruang } \\
\text { pengelolaan } \\
\text { lapas } \\
\text { gedung } 2\end{array}$} & $\begin{array}{l}\text { R. Unit } \\
\text { registrasi dan } \\
\text { bimbingan } \\
\text { kemasyarakat } \\
\text { an }\end{array}$ & \multirow[t]{6}{*}{$\begin{array}{l}\text { Semi } \\
\text { security } \\
\text { area }\end{array}$} & $\begin{array}{l}\text { Maksim } \\
\text { um }\end{array}$ \\
\hline & & $\begin{array}{l}\text { R. Unit } \\
\text { perawatan } \\
\text { lapas }\end{array}$ & & Medium \\
\hline & & $\begin{array}{l}\text { R. Unit } \\
\text { pelatihan } \\
\text { kerja dan } \\
\text { produksi }\end{array}$ & & Medium \\
\hline & & R. TPP & & Medium \\
\hline & & R. KPLP & & $\begin{array}{l}\text { Maksim } \\
\text { um }\end{array}$ \\
\hline & & R. Portir & & $\begin{array}{l}\text { Maksim } \\
\text { um }\end{array}$ \\
\hline \multirow[t]{2}{*}{6.} & \multirow[t]{2}{*}{$\begin{array}{l}\text { R. } \\
\text { Kunjungan }\end{array}$} & $\begin{array}{l}\text { Kunjungan } \\
\text { formal sekat }\end{array}$ & \multirow{2}{*}{$\begin{array}{l}\text { Semi } \\
\text { security } \\
\text { area }\end{array}$} & $\begin{array}{l}\text { Maksim } \\
\text { um }\end{array}$ \\
\hline & & $\begin{array}{l}\text { Kunjungan } \\
\text { formal }\end{array}$ & & $\begin{array}{l}\text { Minimu } \\
\mathrm{m}\end{array}$ \\
\hline
\end{tabular}

\begin{tabular}{|c|c|c|c|c|}
\hline & & $\begin{array}{l}\text { Kunjungan } \\
\text { non formal }\end{array}$ & & Medium \\
\hline \multirow[t]{6}{*}{7.} & \multirow[t]{6}{*}{$\begin{array}{l}\text { Hunian } \\
\text { anak didik }\end{array}$} & $\begin{array}{l}\text { Hunian anak } \\
\text { tahanan }\end{array}$ & \multirow[t]{6}{*}{$\begin{array}{l}\text { Security } \\
\text { area }\end{array}$} & $\begin{array}{l}\text { Maksim } \\
\text { um }\end{array}$ \\
\hline & & $\begin{array}{l}\text { Hunian anak } \\
\text { orientasi }\end{array}$ & & $\begin{array}{l}\text { Maksim } \\
\text { um }\end{array}$ \\
\hline & & $\begin{array}{l}\text { Hunian anak } \\
\text { pembinaan }\end{array}$ & & Madium \\
\hline & & $\begin{array}{l}\text { Hunian anak } \\
\text { asimilasi }\end{array}$ & & $\begin{array}{l}\text { Minimu } \\
\mathrm{m}\end{array}$ \\
\hline & & $\begin{array}{l}\text { Hunian anak } \\
\text { wanita }\end{array}$ & & $\begin{array}{l}\text { Maksim } \\
\text { um }\end{array}$ \\
\hline & & $\begin{array}{l}\text { Hunian anak } \\
\text { strapsel }\end{array}$ & & $\begin{array}{l}\text { Maksim } \\
\text { um }\end{array}$ \\
\hline \multirow[t]{5}{*}{8.} & \multirow[t]{5}{*}{ Pembinaan } & $\begin{array}{l}\text { Pembinaan } \\
\text { spiritual }\end{array}$ & \multirow[t]{5}{*}{$\begin{array}{l}\text { Security } \\
\text { area }\end{array}$} & Medium \\
\hline & & $\begin{array}{l}\text { Pembinaan } \\
\text { intelektual }\end{array}$ & & Medium \\
\hline & & $\begin{array}{l}\text { Pembinaan } \\
\text { fisik }\end{array}$ & & Medium \\
\hline & & $\begin{array}{l}\text { Pembinaan } \\
\text { berkesenian }\end{array}$ & & Medium \\
\hline & & $\begin{array}{l}\text { Pembinaan } \\
\text { kemandiriian }\end{array}$ & & Medium \\
\hline \multirow[t]{5}{*}{9.} & \multirow[t]{5}{*}{$\begin{array}{l}\text { Pelayanan / } \\
\text { servis }\end{array}$} & Poliklinik & \multirow[t]{2}{*}{$\begin{array}{l}\text { Security } \\
\text { area }\end{array}$} & $\begin{array}{l}\text { Maksim } \\
\text { um }\end{array}$ \\
\hline & & Dapur & & $\begin{array}{l}\text { Maksim } \\
\text { um }\end{array}$ \\
\hline & & $\begin{array}{l}\text { Mekanikal } \\
\text { dan elektrikal }\end{array}$ & \multirow{3}{*}{$\begin{array}{l}\text { Semi } \\
\text { security } \\
\text { area }\end{array}$} & Medium \\
\hline & & Garasi & & $\begin{array}{l}\text { Minimu } \\
\mathrm{m}\end{array}$ \\
\hline & & Koperasi & & $\begin{array}{l}\text { Maksim } \\
\text { um }\end{array}$ \\
\hline
\end{tabular}

Hasil dari pembagian zona kemanan berupa zona keamanan secara tegas. Zona security mendapatkan pengamanan berlapis sedangkan zona non security hanya satu lapis.

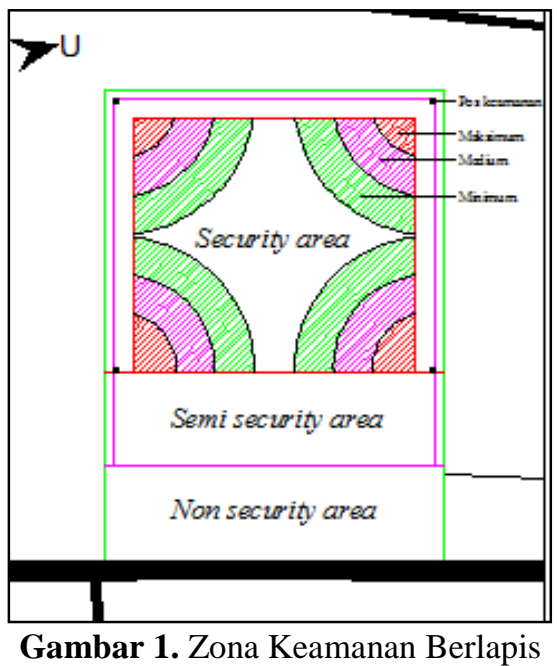

3.3.2 Anaslisa Entrance, Orientasi dan Sirkulasi.

Tapak LPA DIY hanya bisa dicapai dari Jalan Kaliurang, sehingga entrance ke tapak melalui sisi tapak di tepi Jalan 
Kaliurang menuju non security area. Kegiatan keluar masuk dapat digolongkan menjadi 2 yaitu kegiatan internal dan umum. Kegiatan internal antara lain : penerimaan pelepasan anak didik, servis dan penanggulangan bahaya. Kegiatan umum antara lain kegiatan perkantoran pengelola, kegiatan pengununjung dan anak didik asimilasi.

Jumlah entrance untuk zona semi security dan security area dibatasi hanya 1 buah untuk sirkulasi manusia dan 1 buah untuk sirkulasi kendaraan. Hal ini untuk mempermudah pengawasan pertugas terhadap sirkulasi keluar masuk di area LPA DIY.

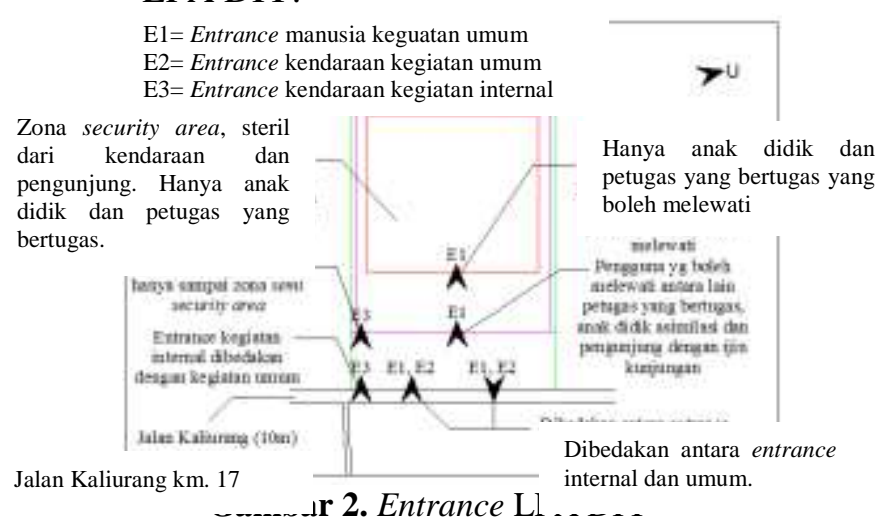

Analisa orientasi dilakukan terhadap keseluruhan tapak kompleks sehingga dicapai kesatuan yang mendukung pencapaian dan orientasi ke masing-masing wadah Hanya anak didik asimilasi, Kendaraan dinas hanya antara lain: petugas yang bertugas dan $\begin{array}{lll}\text { sampai semi security area } & \text { pengunjung dengan ijin } \\ \text { Entrance kegiatan internal } & \text { ermudah } & \text { kunjungan yang boleh }\end{array}$ Entrance kegiatan internal :nali bangunan melewati

b. Mempermudah pengamanan LPA DIY

c. Memberikan efek kebersamaan dalam lingkup lapas

Main entrance dari Jalan Kaliurang membuat bangunan paling dekat dengan jalan menjadi perhatian utama pengunjung. Keadaan ini dimanfaatkan untuk memberikan kesan pada pengunjung tentang lembaga pemasyarakatan. Bangunan pengelolaan gedung 1, yang merupakan bangunan paling depan diberikan arah orientasi ke luar. Kesan yang ingin ditonjolkan adalah kewibawaan, keadilan dan keterbukaan.

Orientasi bagian dalam lapas menggunakan orientasi terpusat di mana pusat orientasi diletakkan pada bangunan pembinaan yang berupa ruang terbuka. Orientasi yang terpusat di tengah tapak untuk memudahkan pengawasan terhadap kegiatan pelaku pemasyarakatan. Orientasi terpusat juga meningkatkan intensitas pertemuan antar pelaku pemasyarakatan. Hal ini mendukung konsep LPA DIY yaitu menanamkan kebersamaan untuk menumbuhkan toleransi pada anak didik.

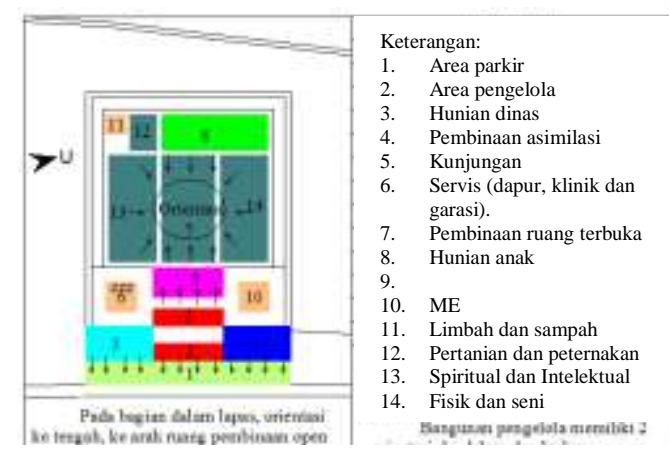

Pada bagian dalam LPA DIY, orientasi terpusat ke a rah ruang terbuka. Bagian luar LPA DIY, orientasi kea rah Jalan Kaliurang.

Gambar 3. Orientasi LPA DIY.

Sirkulasi antara kegiatan internal dan umum dibedakan. Jalur sirkulasi linier di luar zona security area untuk mempermudah pencapaian dan pengawasan serta menyesuaikan dengan arah orientasi bangunan. Untuk bagian dalam menggunakan sirkukasi memutar, mengelilingi ruang terbuka yang digunankan untuk orientasi.

Ruang antara pagar tembok dan pagar pembatas sisi dalam, digunakan untuk jalur pengawasan petugas. Jalur sirkulasi ini steril dari segala bentuk kegiatan kecuali kegiatan pengawasan berkala oleh petugas.
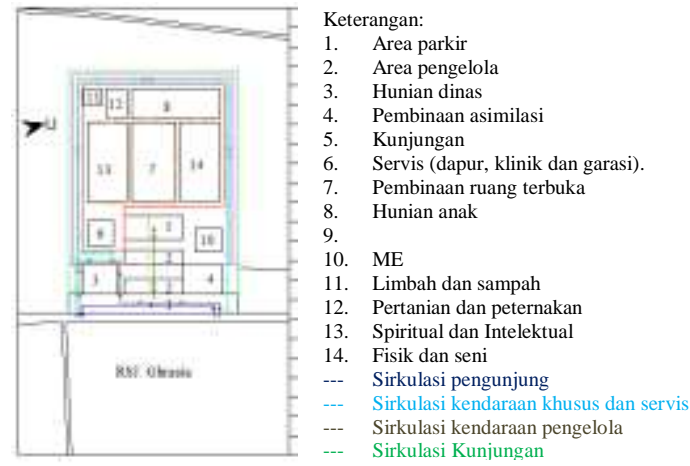

Gambar 4. Sirkulasi LPA DIY. 


\subsubsection{Pemintakatan Akhir}

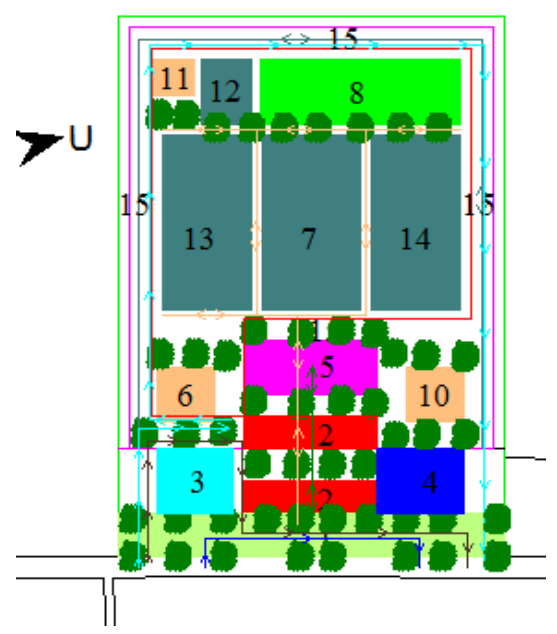

Gambar 5. Pemintakatan LPA DIY

\subsection{Analisa Bentuk Dasar dan Tata Masa}

Kriteria yang harus dipenuhi dalam merancang bentuk dan penataan masa bangunan dalam LPA DIY antara lain:

1. Mudah dalam pengawasan oleh petugas LPA DIY.

2. Membuat ruang yang efektif untuk kegiatan.

3. Bentuk tidak berbelit-belit, mudah diterjemahkan oleh pengguna.

4. Menyesuaikan dengan kegiatan dan pengguna yang diwadahi.

5. Mendukung program pembinaan kebersamaan.

Secara psikologis, manusia akan menyederhanakan lingkungan visual untuk memudahkan pemahaman. Dalam komposisi bentuk, cenderung mengurangi subyek utama dalam pandangan ke dalam bentuk-bentuk yang sederhana dan teratur. Semakin sederhana dan teratur suatu wujud, semakin mudah diterima dan dimengerti. (Ching, 2000)

LPA DIY menggunakan bentuk dasar segi empat yang dipadukan dengan segitiga untuk bagian atapnya. Hal ini digunakan untuk mempermudah pengguna menterjemahkan bentuk sehingga bangunan mudah dipahami. Bentuk segitiga, sebagai respon keadaan klimatologis serta bentuk yang lazim yang biasa ditemui pengguna pada kehidupan sehari hari.

Masa majemuk dipilih untuk mengurangi tingkat stress pada pengguna karena menciptakan banyak ruang terbuka. Masa majemuk memerlukan pengawasan yang lebih. Hal ini diantisipasi dengan menempatkan masa secara lurus mengelilingi orientasi dan meminimalisir ruang antar bangunan yang tidak terawasi dengan memodifikasi bentuk dasar.

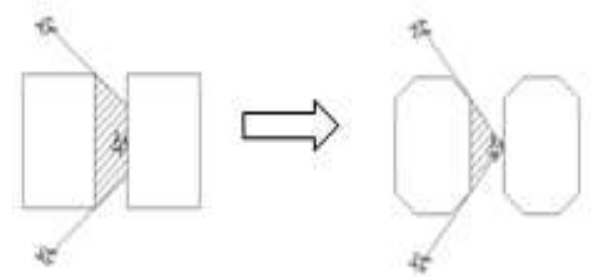

Gambar 6. Modifikasi bentuk dasar

Masa hunian menggunakan komposisi penataan ruang terpusat dengan ruang bersama sebagai pusat orientasi. Hal ini digunakan untuk menumbuhkan rasa kebersamaan dengan membuat anak didik dapat saling berinteraksi namun masih dapat dikontrol oleh petugas.

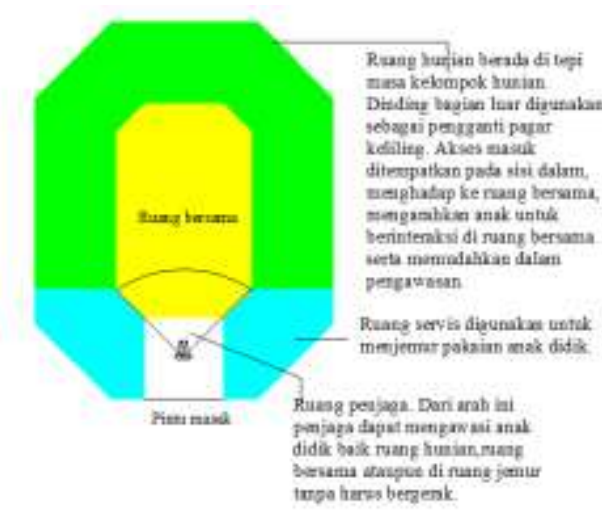

Gambar 7. Pemintakatan Masa Hunian

Masa bangunan pembinaan intelektual dan seni menggunakan pola penataan ruang terpusat dengan taman terbuka hijau sebagai pusat orientasi. Penataan terpusat mengurangi tekanan pada anak didik saat melakukan pembinaan. 


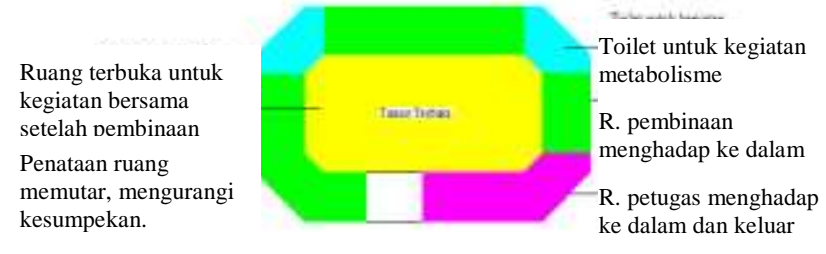

Gambar 8. Pemintakatan Masa Pembinaan

Masa bangunan pengelolaan menggunakan pola penataan ruang linier untuk mempermudah pengawasan dan meningkatkan efektifitas kerja petugas dan membuat keteraturan.

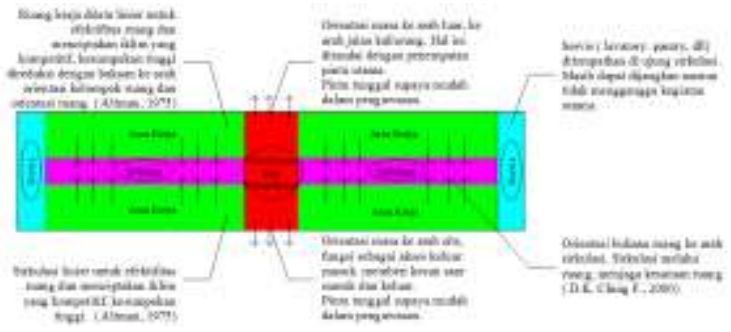

Gambar 9. Pemintakatan Masa Pengelolaan

\subsection{Analisa Pengolahan Ruang}

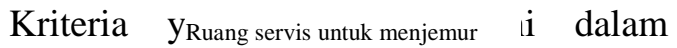
merancang pakaian anak didik an ruang dalam ruang hunian LPA DIY antara lain :

1. Mudah dalam pengawasan oleh petugas LPA DIY.

2. Membuat ruang yang efektif untuk kegiatan.

3. Bentuk tidak berbelit-belit, mudah diterjemahkan oleh pengguna.

4. Menyesuaikan dengan kegiatan dan pengguna yang diwadahi.

5. Mendukung program pembinaan kebersamaan.

Ruang hunian adalah tempat di mana anak didik ditempatkan selama masa pembinaan. Mulai tahap tahanan, orientasi, pembinaan, hingga asimilasi. Anak didik yang melakukan tidakan perilaku menyimpang hingga sampai pada LPA adalah anak-anak yang gagal memenuhi tuntutan masa remajanya. Karakteristik anak hingga melakukan perilaku menyimpang antara lain (N, Yusuf L, 2007) :

1. Lemah untuk proteksi diri dari lingkungan.

2. Kurang bisa menyesuaikan diri dengan lingkungan

3. Pengetahuan tentang nilai dan norma kurang memadai.

Karakteristik seperti di atas, memerlukan pengawasan dan pengarahan dari luar diri namun tidak menekan. Anak pada masa ini memiliki kecenderungan menutup diri dan memiliki ruang personal yang luas, yang dia merasa tidak nyaman ketika orang lain

\section{memasuki teritorinya.}

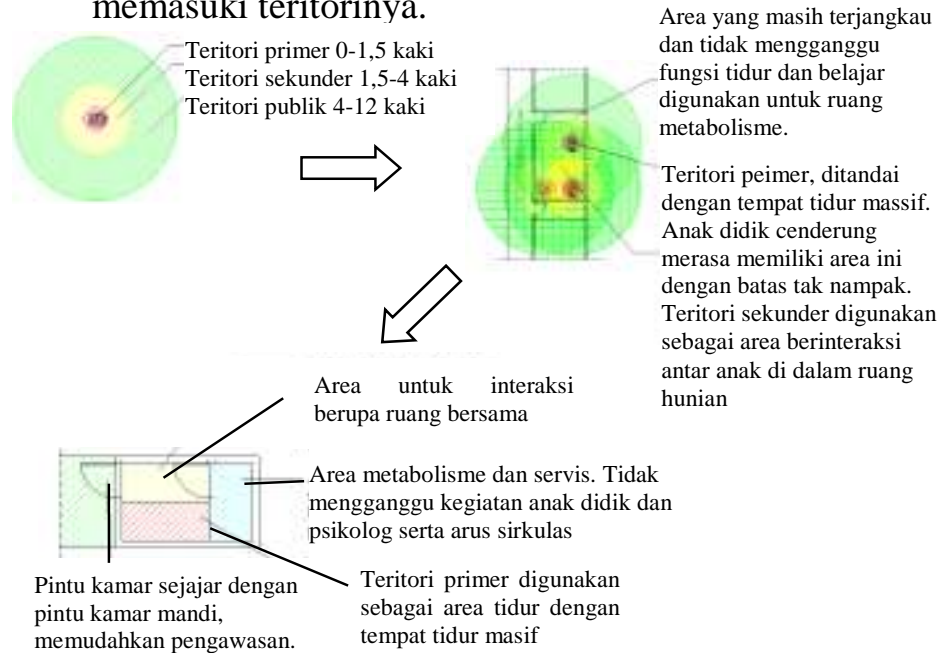

Gambar 10. Penataan Hunian Anak Didik

\subsection{Analisa Suasana Ruang}

Ruang adalah bagian paling dekat dengan pengguna dan mempengaruhi pengguna secara langsung. Ruang disesuaikan dengan fungsi dan karakter pengguna namun tetap aman dan mudah diawasi oleh petugas. Kriteria perancangan ruang antara lain:

1. Mudah dalam pengawasan oleh petugas lapas.

2. Membuat ruang yang efektif untuk kegiatan.

3. Bentuk tidak berbelit-belit, mudah diterjemahkan oleh pengguna.

4. Menyesuaikan dengan kegiatan dan pengguna yang diwadahi.

5. Mendukung program pembinaan kebersamaan.

6. Meminimalisir penyalah gunaan material interior untuk hal-hal yang menyimpang.

Pembentukan suasana ruang memanfaatkan variabel-variabel independen pembentuk ruang antara lain: tekstur, warna, ukuran, bentuk, perabot, suara, temperatur dan pencahayaan. 
1. Ruang Dalam Hunian

Tekstur pada ruang hunian halus, memberikan kesan lembut pada anak didik. Penggunaan terali besi untuk bagian atap, dikamuflase dengan menggunakan plafond. Terali besi pada pintu, jendela dan ventilasi didesain dengan menggunakan bentuk lengkung yang mewakili karakteristik anak didik yang dinamis. Hal ini untuk meminimalisir ekspos jeruji besi yang memberikan efek negatif pada psikologis anak didik.

Dimensi ruang normal dengan menyeimbangkan antara lebar dan tinggi membuat ruang tidak memberikan sebuah penekanan pada anak didik. Dominasi warna hijau terang, digunakan untuk mereduksi tingkat emosional anak setelah melakukan pembinaan selama sehari dan juga memaksimalkan pemantulan cahaya sehingga ruang terlihat terang dan memberikan efek ruang yang luas . Peletakan pintu kamar dengan kamar mandi sejajar untuk mempermudah pengawasan petugas dari luar ruangan. Perabot yang digunakan fix untuk mencegah penyalahgunaan perabot seperti untuk melarikan diri, menyerang orang lain dan menyimpan barang yang dilarang. Penggunaan perabot non fix menyebabkan banyak resiko kemanan.

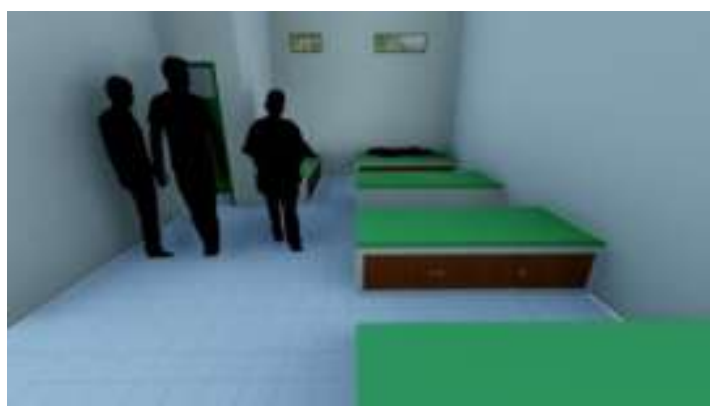

Gambar 12. Suasana Ruang Hunian

2. Ruang Luar di Dalam Area Pembinaan

Kesan yang dibentuk dari ruang luar ini kebersamaan, ramah, tidak menekan namun mudah dalam pengawasan oleh petugas. Ramah disini diartikan sebagai perasaan nyaman seperti di lingkungan tinggal yang wajar.

Bentuk segi empat dipilih dengan pertimbangan karakter bentuk formal dan netral, namun sederhana. Semakin sederhana dan teraturnya suatu wujud, semakin mudah diterima dan dimengerti (Ching, Francis D.K., 2000).

Pemilihan warna terang untuk masa bangunan memberikan kesan luas pada ruang luar. Warna hijau memberikan kesan natural, empati, sejuk dan kesinambungan dengan alam. Warnawarna cerah, digunakan sebagai aksen saja.

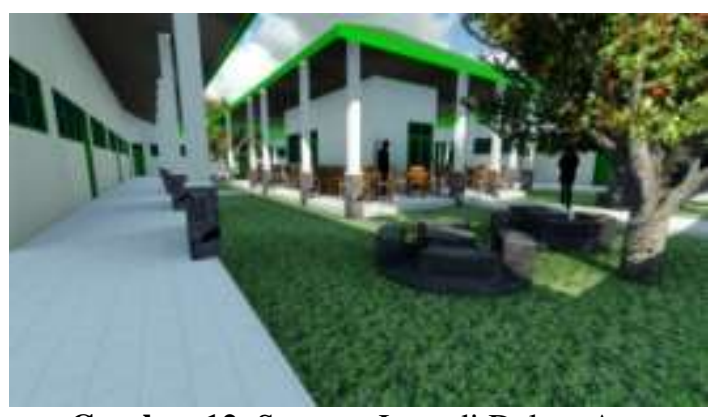

Gambar 12. Suasana Luar di Dalam Area Pembinaan

3. Ruang Luar di Luar Area Pembinaan

Ruang ini terbentuk area non security, di depan bangunan pengelolaan gedung satu hingga Jalan Kaliurang.

Menggunakan bentuk dasar segi empat. Mengurangi subyek utama dalam pandangan ke bentuk-bentuk yang sederhana dan teratur dalam mengkomposisikan bentuk. Kesan ramah dan bersahabat dengan menggunakan bentuk yang biasa dijumpai pengunjung membuat pengunjung merasa nyaman untuk datang.

Menggunakan tipe bangunan tropis dengan teras dan tritisan yang lebar untuk membentuk ruang. Hal ini memberikan efek responsif terhadap iklim setempat dan membuat pengunjung terbiasa karena sering menjumpai tipe bangunan seperti ini setiap harinya. Material transparan digunakan 
untuk mendukung kesan terbuka dari bangunan pembentuk ruang ini. Penataan ruang luar seperti ini ditujukan untuk memperbanyak jumlah pengunjung yang mengunjungi anak didik. Semakin banyak pengunjung yang hadir, maka akan lebih mendukung konsep pembinaan kebersamaan.

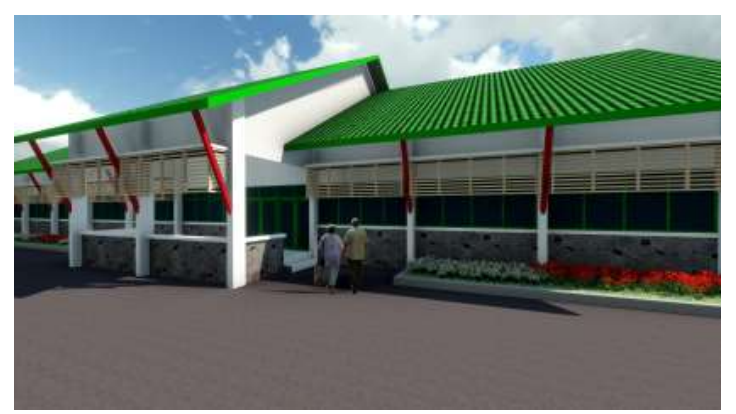

Gambar 13. Suasana Luar di Luar Area Pembinaan

\section{KESIMPULAN (KONSEP DESAIN)}

Analisa LPA DIY pada akhirnya menghasilkan sebuah konsep desain sebuah LPA untuk mewadahi fungsi pemasyarakatan anak di DIY. Konsep desain tersebut antara lain :

Nama Lapas : Lembaga Pemasyarakatan Anak Kelas II A Daerah Istimewa Yogyakarta.

Lokasi : Jl. Kaliurang Km. 11, Kec. Pakem, Kab. Sleman, Propinsi Daerah Istimewa Yogyakarta.
Luas Lahan
: $43.750 \mathrm{~m}^{2}$
Luas Bangunan
: $17201,88 \mathrm{~m}^{2}$
Pelaku Kegiatan
: Anak didik

pemasyatakatan usia 12-18 tahun, petugas

masyarakatan dan masyarakat.

Kegiatan yang Diwadahi : Pengelolaan lapas, kunjungan masyarakat, pembinaan anak didik, hunian, dan servis Pengolahan Tapak:

1. Tapak dibagi menjadi 3 zona keamanan yaitu non security, semi security dan security area.

2. LPA DIY memiliki 2 orientasi. Orienta si luar ke arah Jl. Kaliurang dan orientasi dalam menggunakan orientasi terpusat ke arah ruang terbuka.

3. Sirkulasi dibedakan antara sirkulasi internal dan sirkulasi umum.
Bentuk Dasar dan Tata Masa:

1. Bentuk dasar segi empat yang dipadukan dengan segitiga pada bagian atapnya.

2. Menggunakan masa majemuk untuk mengurangi tingkat stress pada pengguna karena menciptakan banyak ruang terbuka.

3. Masa hunian dan pembinaan menggunakan komposisi terpusat.

4. Masa pengelola menggunakan komposisi linier.

Pengolahan Ruang: Ruang hunian terbentuk dari ruang personal anak didik yang disatukan menjadi ruang dengan pemersatu berupa ruang bersama.

Suasana Ruang:

1. Ruang Hunian: Tekstur halus, teralibesi bagian atas di atas plafon dan bagian bukaan berupa garis lengkung, warna hijau terang, dimensi ruang normal, serta perabot yang ditata fix.

2. Ruang Luar di Dalam Area Pembinaan: Kesan yang dibentuk kebersamaan, ramah, tidak menekan namun mudah dalam pengawasan, bentuk dasar segi empat, warna dominan hijau terang, meminimalisasi penggunaan ornamen.

3. Ruang Luar di Luar Area Pembinaan: Bentuk dasar segi empat, tipe bangunan tropis, menggunakan material yang sering dijumpai masyarakat, dominasi material transparan.

\section{REFERENSI}

Ching,Francis D.K., 2000, Bentuk, Ruang, dan Tatanan, Airlangga, Jakarta.

Hall, S. Calvin dan Gardner Lindzey, 1993, Teori-Teori Psikodinamik (Klinis), Kanisius, Yogyakarta.

Haryadi dan B. Setyawan, 2010, Arsitektur, Lingkungan dan Perilaku, Gadjah Mada University Press, Yogyakarta.

N, Syamsu Yusuf L, 2007, Psikologi Perkembangan Anak dan Remaja, Bandung: Remaja Rodsa Karya. 